\title{
Social Security As a Wage Subsidy Over The Life Cycle
}

\author{
by Harris Schlesinger*
}

\section{Introduction}

The benefits received under Social Security Old-Age and Survivors Insurance depend upon the earnings history of the earnings history of the individual. Several recent papers have argued that the Social Security payroll tax has a high yield when benefits are collected upon retirement. (cf. Burkhauser and Turner [1981a] and Blinder, Gordon and Wise [1980]). Consequently, Social Security provides a subsidy to work effort during a person's working life. This paper incorporates this subsidy into a life-cycle framework in order to examine the effects of Social Security on an individual's lifetime labor decision.

The individual's life-cycle labor-supply decision includes the decision on when to retire. Several recent life-cycle models of Social Security (Sheshinski [1978], Diamond and Mirrless [1978] and Crawford and Lilien [1981]) have modeled retirement as a labor-force-participation decision in which an individual must choose at each point in time whether or not to remain in the labor force. However, the individual is not given the option of working part time. Is is shown in this paper that this restriction distorts the individual's optimal retirement decision.

In the present paper, labor supply is completely variable. In order to focus on the effects of Social Security on the optimal labor path, a model in which the optimal labor path is constant over the life-cycle is first presented. This serves as a "base model" upon which the effects of several variations can be observed.

The nature of Social Security is such that the rules change as one reaches various ages. The advantages and disadvantages of an individual's decision to work either more or less hours are quite different at age 65 than they are at age 40 . The fact that the individual is cognizant of this difference, suggests that a life-cycle modeling of the individual's decision is appropriate.

* International Institute of Management, Berlin. This research was supported by a grant from the Labor-Management Services Administration, Office of Planning and Research of the Pension and Welfare Benefit Program, U.S. Department of Labor. The author would like to thank Richard V. Burkhauser, Alan Blinder, George Sweeney and Roger Gordon for helpful comments on an earlier draft of this paper. 
This paper views Social Security as a wage subsidy on years preceding benefit acceptance. If a constant subsidy exists during early year, it is shown that the individual will choose two different levels of labor supply: a high level of labor supply in early years and a lower level, possibly full retirement, during years when the subsidy is no longer in effect. Necessary and sufficient conditions for this lower level of labor supply being complete retirement are presented. These conditions relate the wage rate, amount of subsidy and duration of the subsidy.

The explicit nature of the subsidy implicit in the Social Security system is introduced next. The model adapts the basic subsidy argument of Blinder, Gordon and Wise [1980]. What they essentially show is that Social Security provides a subsidy of a constant proportion to wages; however, this subsidy is withheld without interest until retirement. Therefore, the current value of the subsidy is less during earlier years of work, assuming a positive rate of interest. In a life-cycle framework, this is shown to cause an increasing flow of labor services during the subsidized years. When only a given number of years are eligible for this subsidy, the question becomes: "Which years will be chosen by the individual?" Blinder, Gordon and Wise suggest that later years are more preferred, although they ignore the life-cycle context. This paper shows that their suggestion holds within a life-cycle framework, and indeed optimal labor supply increases as retirement age approaches.

\section{A basic life-cycle model}

Consider an individual who knows with certainty that his working life spans $T$ years. The individual is allowed to choose his flow of labor services at any point in time. The individual's problem is to choose jointly his optimal life-cycle and consumption paths. It is assumed that the individual has no nonlabor source of income except that he may borrow or lend money at a fixed rate of interest, $r^{1}$

The individual wishes to maximize lifetime utility

$$
\mathcal{V} \equiv \int_{o}^{T} U(c(t)) e^{-\delta t} d t
$$

where

$$
\begin{aligned}
U & \equiv \text { individual's utility function } \\
c(t) & \equiv \text { consumption flow at time } t \\
L(t) & \equiv \text { leisure flow at time } t \\
\delta & \equiv \text { rate of time preference. }
\end{aligned}
$$

Utility is assumed to be strictly concave with

$$
\lim _{c \rightarrow 0} U_{c}(c, L)=\lim _{L \rightarrow 0} U_{L}(c, L)=\infty .^{2}
$$

\footnotetext{
${ }^{1}$ For a discussion of the effects of eliminating the assumption of a perfect capital market, the reader is referred to Crawford and Lilien [1981].

${ }^{2}$ In this notation, $U_{c}$ represents $\partial U / \partial c$ and $U_{L}$ represents $\partial U / \partial L$.
} 
This last condition guarantees a positive flow of $c$ and $L$ throughout the life-cycle. Time not spent at leisure is spent working at wage rate $w$, which is assumed to remain constant over the individual's lifetime in order to focus on Social Security effects. Some comments on relaxing this assumption appear later in the paper. Let $H(t)$ denote time spent at work. Total time available for work or leisure in each period is normalized such that.

$$
L(t)+H(t)=1 .
$$

Leisure is further restricted by the constraint

$$
L(t) \leq 1 \text { (or equivalently } H(t) \geq 0) .
$$

Let $A(t)$ denote the individual's stock of non-consumption-good wealth (i.e., savings) at time $t$. The time path of $A$ is given by

$$
\dot{A} \equiv d A / d t=r A(t)+w H(t)-c(t) .
$$

In the absence of bequests, either from past generations or towards future generations, the endpoint conditions for (5) are

$$
A(0)=A(T)=0
$$

The individual's objective is to maximize (1) subject to constraints (3), (4), (5) and (6). Forming the Hamiltonian and appending it to take account of (4),

$$
\begin{aligned}
\mathcal{L} \equiv e^{-\delta t}[U(c(t), L(t)) & +\mu(t)(r A(t)+w H(t)-c(t)) \\
& +\lambda(t) H(t)] .
\end{aligned}
$$

Necessary conditions for the above maximization are

$$
\begin{array}{ll}
\text { (8) } & U_{c}=\mu(t) \\
\text { (9) } & U_{L}=w \mu(t)+\lambda(t) \\
\text { (10) } & \lambda(t) \cdot H(t)=0, \lambda(t) \\
\text { (11) } & \dot{\mu} \equiv d \mu / d t=(\delta-r) \mu .
\end{array}
$$$$
\text { (10) } \quad \lambda(t) \cdot H(t)=0, \lambda(t) \geq 0
$$

In order to focus on the added effects of Social Security, it is assumed that $U$ is separable and that $\delta=r r^{3}$ In this case, consumption is constant over time, as is labor. Moreover, (2) guarantees that $L(t)<1 .^{4}$

\footnotetext{
${ }^{3}$ See Heckman [1974] for a discussion of the particular effects of relaxing these assumptions.

${ }^{4}$ This follows from (6) since $c(t)>0$.
} 
As an example, consider the utility function $U(c, L)=\ln c+\ln L$. In this case, it is not difficult to show that $L^{*}(t)=H^{*}(t)=1 / 2$ defines the optimal path of labor supply. ${ }^{5}$ This example is later considered as a base case from which deviations are examined. In this example, if the total time available for work or leisure per working day is 14 hours, then the individual's optimal daily labor supply would be seven hours. ${ }^{6}$

\section{Binary labor choice}

In order to generate a more tractable model and to focus on the optimal retirement decision per se, several recent papers have adopted a binary labor choice: Individuals can either work full-time or not work at all. ${ }^{7}$ This assumption forces a "bang-bang" type of solution as the optimal labor path. ${ }^{8}$ The likely result is a distortion of the optimal retirement decision.

Under the assumptions of the previous section, the optimal labor flow was constant over the life-cycle. Let $H^{*}$ denote this optimal level. If the full-time level of labor supply in a binarychoice framework does not exceed $H^{*}$, the individual's optimal labor decision is to work fulltime until death. However, when full-time labor exceeds $H^{*}$, the individual might have an incentive to retire from the work force.

Consider the example used in the preceding section, which is consistent with Sheshinski's [1978] basic model. It is easy to show that the optimal consumption flow is constant in the binary-labor-choice framework. Let $N$ denote the date of full retirement. Once $N$ is chosen, the individual's lifetime budget constraint is determined and consequently so is his level of consumption. The individual's objective can be written as

$$
\underset{N}{\operatorname{Max}} \int_{O}^{T} U(c) e^{-r t} d t+\int_{N}^{T} V e^{-r t} d t
$$

subject to the budget constraint

$$
\int_{O}^{T} c e^{-r t} d t=\int_{O}^{N} w H_{F} e^{-r t} d t
$$

where

$$
V \equiv \text { extra leisure utility obtained during full retirement }
$$

\footnotetext{
${ }^{5}$ In a more general form, if $U(c, L)=\alpha \ln c+\beta \ln L$, then $L^{*}(t)=\beta /(\alpha+\beta)$. The utility function used in the above example is extrapolated from Sheshinski [1978] who basically assumes at least the consumption component of this separable utility function.

${ }^{6}$ It is interesting to note that this occurs independent of the wage rate, $w$. The consumer will adjust his optimal consumption so that $c^{*}(t)=w / 2$.

${ }^{7}$ See, for example, Sheshinski [1978], Diamond and Mirrlees [1978], and Crawford and Lilien [1981].

${ }^{8}$ A discussion of "bang-bang" solutions can be found in Kamien and Schwartz, Dynamic Optimization: The Calculus of Variations and Optimal Control in Economics and Management, North Holland, 1981.
} 
and

$$
H_{F} \equiv \text { full-time level of labor flow. }
$$

Integrating (12) and (13), the individual's objective may be written as

$$
\operatorname{Max}\left(1-e^{-r}\right) U(c)+\left(e^{-r N}-e^{-r T}\right) V
$$

subject to

$$
c=\left[\left(1-e^{-r N}\right) /\left(1-e^{-r T}\right)\right] w H_{F} .
$$

The first order condition for the above maximization is ${ }^{9}$

$$
r e^{-r N}\left(U_{c} w H_{F}-V\right)=0 .
$$

Equation (14) requires the extra utility of consumption generated by working another period equal the marginal utility of leisure from retirement. Assuming $r>0$, if $U$ is defined as in the example in the preceding section, (14) implies

$$
w H_{F}=V c .
$$

Condition (15) determines the optimal value of consumption. Substituting (15) into $\left(13^{r}\right)$ yields an optimal value of $N$, which satisfies

$$
V=\left(1-e^{-r t}\right) /\left(1-e^{-r N}\right) \text {. }
$$

From (16), early retirement occurs if and only if $V>1 .{ }^{10}$ Using the utility function $U(c, L)=\ln c$ $+\ln L, V>1$ if and only if $H_{F}>1-e^{-1} \simeq .63$. Based on a day in which 14 hours are available for either labor or leisure, this critical value of $H_{F}$ amounts to approximately 8 hours and 50 minutes. That is, only if full-time work exceeds 8 hours and 50 minutes per day will early retirement occur. Obviously this critical value is dependent on the particular utility function chosen as well as available time. However, this example shows that an individual who would optimally choose a constant labor-flow of $H^{*}$ - indeed, he might search for a job in which the fulltime labor flow is $H^{*}$ - might retire early due solely to the restrictiveness of the binary labor choice.

An example is shown in Figure 1. In Figure 1, the dashed line indicates the optimal-laborsupply path when full time labor, $H_{F}$, exceeds the critical value of .63 . The solid line indicates an optimal path for a full-time level of labor supply, $H_{F}^{r}$, that does not exceed this critical value. Note that there is some degree of tolerance for a higher level of full-time labor than desired. In particular, recall that the desired supply of labor is $H^{*}=.5$. If $.5<H_{F} \leq .63$, the individual would not choose early retirement, even though $H_{F}$ exceeds $H^{*}$.

\footnotetext{
${ }^{9}$ The second order condition is easily verified.

${ }^{10}$ The assumption $V>1$ is made by Sheshinski [1978].
} 


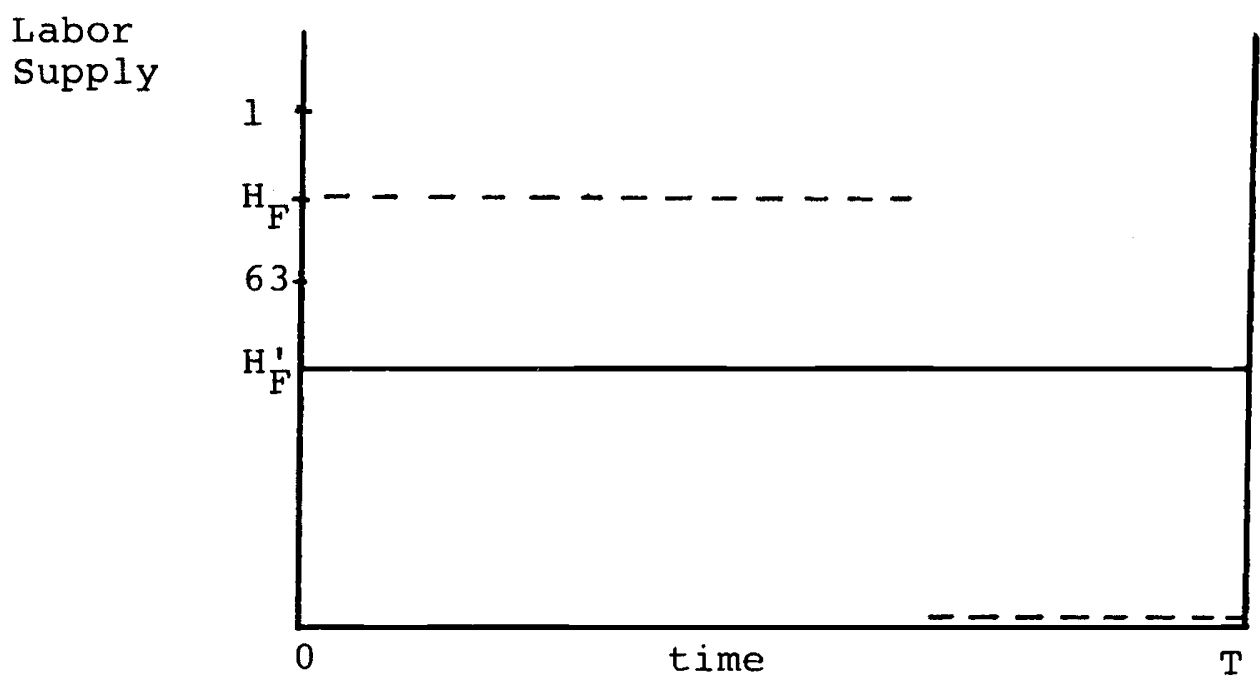

Figure 1

\section{A wage subsidy in early years}

If Social Security is actuarially fair in that payroll deductions taken out of the worker's pay in early years are returned dollar for dollar with interest upon retirement, there is no effect on the individual's optimal labor choice since his lifetime budget constraint is not affected." However, employer tax contributions, actuarial adjustments in later years, the "pay-as-yougo" nature of Social Security financing and the earnings test in later years all work against the notion of actuarial fairness. Two recent papers, Blinder, Gordon and Wise [1980] and Burkhauser and Turner [198la], treat Social Security as essentially the same as a wage subsidy in early years. Before turning to the explicit nature of the Social Security program on life-cycle wages, the effects of a constant wage subsidy in early years are examined. The following section will incorporate the Blinder, Gordon and Wise type subsidy into a life-cycle framwork.

Consider a wage subsidy which adds a constant proportional amount, $\alpha$, to the wage rate up to time $t^{*}<T$.

$$
w(t) \equiv \begin{cases}(1+\alpha) w & \text { for } t<t^{*} \\ w & \text { for } t \geq t^{*}\end{cases}
$$

If $\alpha<0$, there exists a pure tax on labor in earlier years. For our purpose, $\alpha$ is assumed to be positive. Also, the utility function used in the previous example is assumed throughout the remainder of this section.

1" This assumes the assumptions made in section 2. For example, the nonexistence of an available market for borrowing would effect a nonconstant level of lifetime consumption. 
Modifying (5) and (7) to take the subsidy into account, the optimal consumption choice is again to consume at a constant rate. However, the optimal labor flow involves a decrease in labor supply at $t^{*}$. The optimal labor supply is given by

$$
H^{*}(t)=\left\{\begin{array}{l}
1-[c /(w+\lambda)] \text { for } t \geq t^{*} \\
1-[c /(1+\alpha) w] \text { for } t<t^{*}
\end{array}\right.
$$

where $\lambda H^{*}(t)=0$.

If an interior solution exists $\left(H^{*}>0\right.$ for all $\left.t\right)$, then it can be shown that

$$
H^{*}(t)= \begin{cases}\left.H^{*}(0)=1-1 / 2[1+\phi \alpha) /(1+\alpha)\right] & \text { for } t<t^{*} \\ H^{*}(T)=1 / 2(1-\phi \alpha) & \text { for } t \geq t^{*}\end{cases}
$$

and

$$
c^{*}(t)=1 / 2(1+\phi \alpha) w
$$

where

$$
\phi \equiv\left(1-e^{-n^{*}}\right) /\left(1-e^{-r T}\right) \cdot{ }^{12}
$$

Figure 2

\section{Labor}

Supply

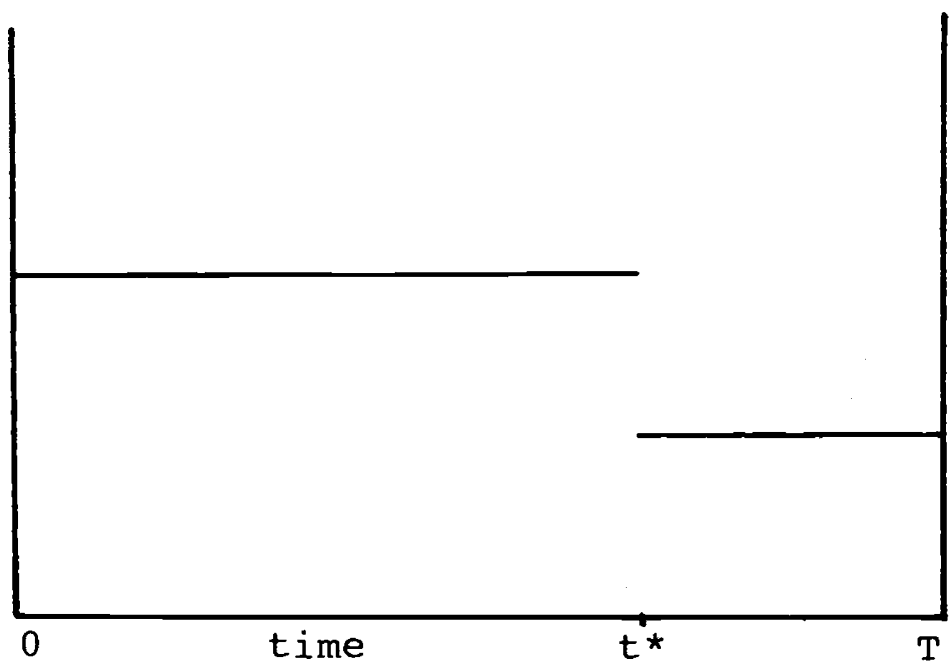

${ }^{12}$ Note that $\alpha=0$ yields a solution identical to the previous example. This definition of $\phi$ is analogous to the inverse of the variable of the same name in Sheshinski [1978]. 
Note that the individual now works longer hours in earlier years and less in later years. ${ }^{13}$ This result is not surprising given existing results in the literature on life-cycle labor response to a changing wage pattern. ${ }^{14}$ The difference here is in interpreting the change in wages as due to a subsidy. An optimal time path for labor supply is illustrated in Figure 2.

Interpreting $\phi$, consider a one-dollar flow of income for life. The present value of this flow at $t=0$ is $\int_{o}^{T} e^{-r t} d t$. If this flow were to stop at time $t^{*}$, the present value would be $\int_{0}^{t^{*}} e^{-r t} d t$. $\phi$ equals the ratio of these two integrals; i.e., $\phi$ is the relative value of a subsidy-dullar flow to a wage-dollar flow over the life-cycle. Put another way, receiving a flow of $\$ \phi$ for life is equivalent, in terms of present value, to receiving a $\$ 1$ flow for $t *$ years.

It is apparent from (19) and (20) that

(i) an increase in $w$ has no effect on the optimal labor supply, only on optimal consumption;

(ii) an increase in $\alpha$ causes both $H^{*}(0)$ and $H^{*}(T)$ to fall;

and (iii) an increase in $t^{*}$ causes both $H^{*}(0)$ and $H^{*}(T)$ to fall. However, the higher labor flow of $H^{*}(0)$ is supplied for a longer span of time. The net effect on total lifetime labor supply is ambiguous. ${ }^{15}$

The above analysis assumes that the optimal labor path is not constrained by (4). Since $c^{*}>0$, the nonnegative labor constraint, (4), if binding, would imply that $H^{*}(T)=0$. In this case, full retirement occurs at time $t^{*}$. The optimal flow of labor services in earlier years, given full retirement at time $t^{*}$, is

$$
H^{*}(0)=1 /(1+\phi) \text {. }
$$

Note that changes in $w$ or $\alpha$ no longer affect the optimal labor path. However, this is valid only so long as full retirement occurs. From (19), full retirement will occur if and only if

$$
\phi \alpha \geq 1 .^{16}
$$

This seems infeasible in our model since it requires a wage subsidy exceeding the wage itself.

\section{Social security as a wage subsidy}

Burkhauser and Turner [1981a] argue that the Social Security payroll tax, when viewed as forced savings, has a high marginal yield when benefits are collected upon retirement. They calculate that this high yield renders the so-called payroll "tax" into a net subsidy, when

\footnotetext{
${ }^{13}$ Note that $H^{*}(0)>H^{*}(T)$. Also, note that $(1+\alpha) w H^{*}(0)>c^{*}(t)>w H^{*}(T)$.

${ }^{14}$ See, for example, Heckman [1974] and [1976] and Blinder and Weiss [1976].

${ }^{15}$ In all three cases above, $c$ will rise. These results are straightforward since $\phi<1$ and $\phi^{\prime}(t)>0$.

${ }^{16}$ If (22) holds, the value of the subsidy for $t^{*}$ years exceeds the value of the wage rate for $T$ years. In our model, (22) seems implausible. Thus, full retirement should not occur optimally. However, once transactions costs of employment are considered, it may be the case that small amounts of works effort won't meet these costs (such as transportation costs). Consequently, consideration of these costs may alter the above conclusions.
} 
viewed over the life-cycle. Blinder, Gordon and Wise [1980] examine the effects of automatic benefit recomputation (ABR) in work incentives. ${ }^{17}$ They show that ABR causes a subsidy to the wage rate. Both of these papers stop short of considering the effects of their findings on life-cycle labor decisions.

Much has been said on both sides regarding the issue of whether or not Social-Securitybenefit adjustments are actuarially fair between the ages of 62 and 65 . This question is not addressed in the present paper. ${ }^{18}$ It is well established, however, that actuarial penalties after age 65 , along with the earnings test, more than offset any benefits of a wage subsidy. ${ }^{19}$ The purpose below is to study the effects of this induced wage subsidy on the optimal lifetime labor path.

As a first step, suppose that the subsidy lasts through period $t^{*}$. Unlike the previous section, however, the subsidy is assumed to be constant in dollars paid at time $t^{*}$. That is, each extra dollar's worth of labor supplied receives a subsidy of $\$ \alpha$ paid at time $t^{*}{ }^{20}$ Since work effort in earlier periods encounters a longer wait until subsidy benefits are realized, the present value of the subsidy is lower in earlier periods. In particular,

$$
w(t)= \begin{cases}{\left[1+\alpha e^{-r\left(t^{*}-t\right)}\right] w} & \text { if } t<t^{*} \\ (1-\theta) w & \text { if } t \geq t^{*}\end{cases}
$$

where $\theta$ denotes an effective tax rate (including the earnings test) on income received after time $t^{*}$. Note that $w(t)$ is increasing in $t$ through period $t^{*}$. Also, note that putting $\$ \alpha e^{r\left(t^{*}-t\right)}$ into savings at time $t$ yield $\$ \alpha$ at time $t^{*}$. Due to the existence of perfect capital markets, the subsidy from an extra unit of labor has the same effect on the life-time budget constraint regardless of which period it occurs in for $t<t^{*}$.21

The optimal consumption and labor paths are given by ${ }^{22}$

$$
c^{*}(t)=1 / 2[1+\psi \alpha-(1-\phi) \theta] w
$$

${ }^{17}$ Automatic benefit recomputation is the method of adjusting future Social Security benefits for current work effort.

${ }^{18}$ To get a flavor of the controversy, the interested reader is referred to Burkhauser and Turner [1981b]

${ }^{19}$ The earnings test is essentially a tax which reduces current benefits when the benefit recipient has current labor income.

${ }^{20}$ More realistically, the present value of the flow of benefits until death is $\$ \alpha$ at time $t^{*}$. However, this distinction is of no consequence to the present results. Thus, one may think of all Social Security benefits being paid out at time $t^{*}$.

${ }^{21}$ Blinder, Gordon and Wise incorrectly consider the subsidy to be more valuable as $t$ approaches $t^{*}$, since the current value of the subsidy is higher. This need not be the case as is shown in the following section of the paper.

${ }^{22}$ This assumes $U(c, L)=\ln c+\ln L$. The derivation of these conditions is presented in the appendix. These conditions assume an interior solution $(H(t)>0$ for all $t)$. Using any separable, concave utility function, the basic results still hold. In this case, optimal leisure is determined by

$$
U_{L}=\left\{\begin{array}{l}
{\left[1+\alpha e^{-r\left(t^{*}-t\right)}\right] w / c^{*} \text { for } t<t^{*}} \\
(1-\theta) w / c^{*} \text { for } t \geq t^{*}
\end{array}\right.
$$

Since $U_{L L}<0$, leisure decreases up to age $t^{*}$, after which leisure attains its highest level. 
and

$$
H^{*}(t)= \begin{cases}1-\left[c^{*}(t) /\left(1+\alpha e^{-r\left(t^{*}-t\right)}\right) w\right] & \text { for } t<t^{*} \\ 1-\left[c^{*}(t) /(1-\theta) w\right] & \text { for } t \geq t^{*}\end{cases}
$$

where

$$
\phi \equiv\left(1-e^{-r^{*}}\right) /\left(1-e^{-r T}\right)
$$

and

$$
\psi \equiv\left(r t^{*} e^{r^{*}}\right) /\left(1-e^{-r T}\right) .
$$

Note that $c^{*}(t)$ is constant and $H^{*}(t)$ is constant for $t \geq t^{*}$. For $t<t^{*}, H^{*}(t)$ is increasing in $t$.

From $(25), H^{*}\left(t_{i}\right)<H^{*}\left(t_{j}\right)$ for any $t_{i} \geq t^{*}$ and $t_{j}<t^{*}$. That is, labor supply is at its lowest level from period $t^{*}$ onward. ${ }^{23}$ Labor supply approaches its highest level as $t$ approaches $t^{*}$. An example is shown in Figure 3.

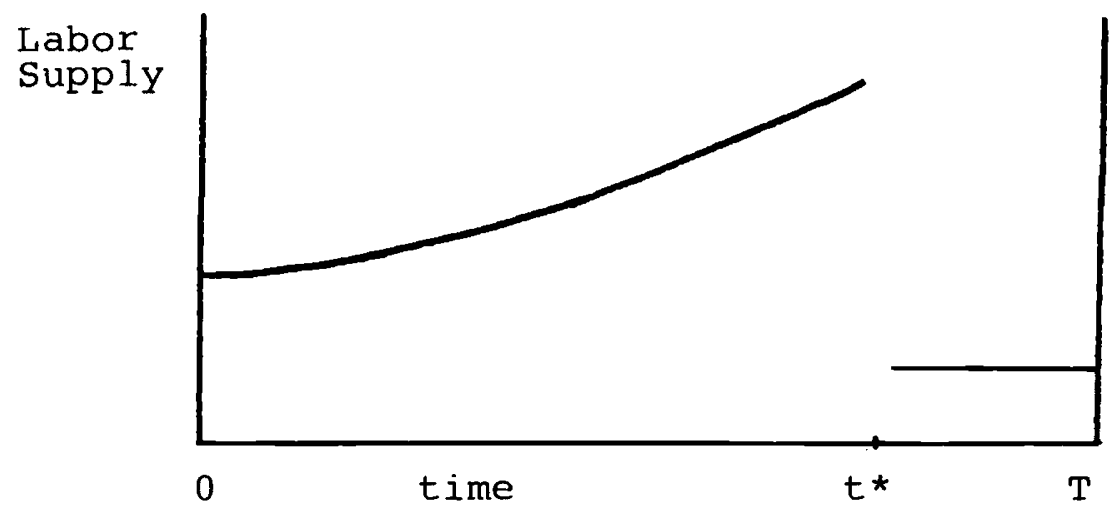

Figure 3

$\phi$ is defined as in the previous section. To interpret $\psi$, note that $\psi=t^{*} e^{-n^{*} /} \int_{O}^{T} e^{-n} d t$. The numerator above is the present value, at $t=0$, of receiving $t^{*}$ dollar at time $t^{*}$. This is the value of receiving a subsidy of $\$ 1$ per period withheld without interest until time $t^{*}$. The denominator is the present value of $\$ 1$ income flow over the life-cycle. In effect, $\psi$ is the relative value of a subsidy dollar to a wage dollar. Thus, for example, (24) expresses consumption as essentially one-half of the "average value" of a unit of labor services, where $1-\phi$ is the weight (relative value of a dollar flow only received from period $t^{*}$ onward) given to the $\operatorname{tax}, \theta$.

${ }^{23}$ This holds so long as $\phi$ and $\alpha$ are not both zero. 
The above analysis assumes that the individual does not choose to fully retire. A necessary and sufficient condition for full retirement is ${ }^{24}$

$$
(\psi \alpha+\phi \theta) \geq(1-\theta)
$$

Consider the individual as facing the tax rate of $\theta$ throughout his life-time. The RHS of (26) represents the full-wealth flow of this individual. ${ }^{25}$ The first term on the $L H S$ above represents the relative value of the subsidy as compared to this full-wealth flow. Since the tax rate, $\theta$, is only effective for $t \geq t^{*}$, the individual may be thought of as being exempt from this tax during the first $t^{*}$ years. The relative value of this exemption, as compared to the full-wealth flow, is given by the second term on the $L H S$ in (26). Thus, the $L H S$ of (26) represents the aggregate value of the subsidy and tax exemption. Only when this value exceeds the value of the full-wage does complete exit from the labor force occur. ${ }^{26}$

\section{Duration of the subsidy}

The actual nature of Social Security is such that the subsidy described in the preceding section is only effective for a subset of the first $t^{*}$ periods. Let $N$ be the number of periods in which this subsidy is in effect, $N<t^{*}{ }^{27}$ If the individual is free to choose which periods the subsidy is in effect, which periods will be chosen?

Since each extra dollar's worth of labor prior to time $t^{*}$ adds $\$ \alpha$ in subsidy benefits to the lifetime budget constraint, regardless of the period in which the extra labor is supplied, the choice of subsidized periods has no effect on the optimal level consumption. Using the example of the previous sections, it can be shown that

$$
c^{*}(t)=1 / 2[1+\zeta \alpha-(1-\phi) \theta] w
$$

where

$$
\zeta \equiv\left(t N e^{-r^{*}}\right) /\left(1-e^{-r T}\right)
$$

$\zeta$ may be interpreted in a manner similar to $\psi$ of the preceding section, the difference being that the relative subsidy value is lower since only $N$ periods of work effort are subsidized. (i.e., $\zeta<\psi$.)

Although the choice of which $N$ periods are chosen does not affect $c^{*}$, it does affect the individual's lifetime utility through the leisure component of utility. Blinder, Gordon and Wise [1980] essentially treat the individual's past work effort as exogenous at any given time.

\footnotetext{
${ }^{24}$ This is derived in the appendix. Compare (26) with (22).

${ }^{25}$ The notion of full wealth is due to Becker [1965]. If the individual worked full-time with no leisure, the resulting income flow would be the $R H S$ of $(26)$ multiplied by the wage rate.

${ }^{26}$ Comparative dynamics yield mostly ambiguous results in this model. This is basically due to the intertemporal nature of the price of leisure, given the mechanics of the subsidy.

${ }^{27}$ The subsidy, which stems from the automatic benefit recomputation, is active for the $N$ years of highest earnings where $N$ is the number of years between 1956 and the year in which age 62 is attained.
} 
They argue that the individual is likely to do better by increasing work effort in the current period. Since the current value of the subsidy is higher in later years, as one approaches $t^{*}$, they argue that work effort should be increased in these later years. Although they ignore the effects of the timing of subsidy acceptance - earlier subsidy acceptance would allow more time for interest to accumulate on the subsidy's current value, yielding $\$ \alpha$ at time $t^{*}$ regardless of when the extra labor is performed - their basic conclusion turns out to be correct. The $N$ years implicitly chosen to receive the wage subsidy would be years $t^{*}-N$ through year $t^{*}$. This is proven in the appendix.

The optimal labor path is given by

$$
H(t)=\left\{\begin{array}{l}
1-\left(c^{*} / w\right) \text { for } t<t^{*}, t \text { not a subsidized period } \\
1-\left[c^{*} /\left(1+\alpha e^{-r\left(l^{*}-t\right)}\right) w\right] \text { for } t \text { a subsidized period } \\
1-\left[c^{*} /(1-\theta) w\right] \text { for } t \geq t^{*}
\end{array}\right.
$$

The optimal labor flow is at its lowest level and is constant for $t \geq t^{*}$. It is at a higher constant level during nonsubsidized periods preceding $t^{*}-N$. The optimal flow is at its highest level and is increasing through the subsidized periods. An example of the optimal labor path is shown in Figure 4.

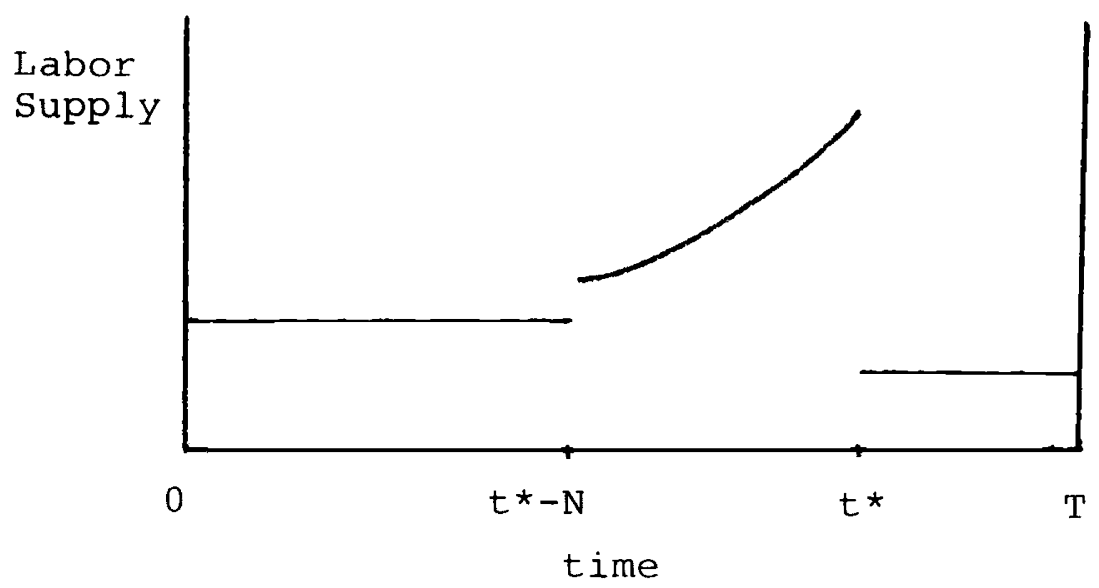

Figure 4

The above analysis holds only if there is not complete exit from the labor force. complete exit occurs if and onldy if

$$
(\zeta \alpha+\phi \theta) \geq(1-\theta)
$$

which may be interpreted in a manner analogous to the interpretation following (26). When complete retirement does occur, the descriptive analysis following (28) still holds. ${ }^{28}$ differ.

${ }^{28}$ The value of $H^{*}(t)$ for $t \geq t^{*}$ will be zero. (28) will still hold for $t<t^{*}$ although the value of $c^{*}$ will 


\section{Concluding remarks}

Under the basic assumptions of a perfect capital market, a rate of time preference equal to the interest rate and no bequest motive, a subsidy causes more labor to be supplied during subsidized periods. Given a subsidy that increase over time, labor supply will also increase. The specific nature of Social Security acts as an increasing subsidy; however, the worker must choose which years are to be subsidized. In general, the work effort will increase throughout the subsidized years and the years chosen for subsidy acceptance will be the later years in the individual's working life.

If we adopt a more realistic wage profile in which the nominal wage (excluding any subsidy) increases over the individual's working life, this will further strengthen the decision to work longer during later years (which is also shown in the appendix).

\section{Appendix}

\section{A. Derivation of the Optimal Labor Path}

The individual's maximization of lifetime utility subject to the budget constraint, (5), and to (23) yields the necessary condition

$$
H^{*}(t)=\left\{\begin{array}{l}
1-c^{*} /\left(1+\alpha e^{-r\left(t^{*}-t\right)}\right) w \text { for } t<t^{*} \\
1-c^{*} /[(1-\theta) w+\lambda] \text { for } t \geq t^{*}
\end{array}\right.
$$

where $\lambda H^{*}(t)=0$.

Assume that $H^{*}(t) \neq 0$ for all $t$. The individual's budget constraint implies that

$$
\begin{aligned}
\int_{0}^{T} c e^{-r t} d t=\int_{0}^{t^{*}}(1 & \left.+\alpha e^{-r\left(t^{*}-t\right)}\right) w H(t) e^{-r t} d t \\
& +\int_{t^{*}}^{T}(1-\theta) w H(t) e^{-r t} d t .
\end{aligned}
$$

Substituting the necessary condition above into this expression,

$$
\begin{aligned}
2 \int_{0}^{T} c e^{-r t} d t=\int_{0}^{l^{*}} w e^{-n} d t & +\alpha e^{-r^{*}} \int_{0}^{l^{*}} w d t \\
& +\int_{\tau^{*}}^{T}(1-\theta) w e^{-r t} d t .
\end{aligned}
$$

Integrating and multiplying both sides by $r /\left[2\left(1-e^{-r T}\right)\right]$,

$$
c^{*}(t)=1 / 2[\phi+\psi \alpha+(1-\phi)(1-\theta)] w
$$

where $\phi$ and $\psi$ are defined as in the text. Combining terms yields (24) in the text. Equation (25) follows directly. 


\section{B. Full Retirement}

Using the above model, complete retirement occurs if and only if $H^{*}(T) \leq 0$, where $H^{*}$ is defined as in (25) and (24). This occurs if and only if

$$
c^{*} \geq(1-\theta) w
$$

if and only if

$$
(1+\psi \alpha) w-(1-\phi) \theta w \geq 2(1-\theta) w
$$

if and only if

$$
\psi \alpha+\phi \theta \geq(1-\theta)
$$

The last inequality above is (26) in the text.

\section{Choice of the Subsidized Periods}

The individual's optimal consumption and labor paths for the case when $N<t^{*}$ periods are subsidized is presented below. Assuming complete retirement does not occur, the first order maximization conditions yield

$$
L^{*}(t)=\left\{\begin{array}{l}
c / w \text { for } t \in\left(0, t^{*}-N-K\right) \text { or } t \in\left(t^{*}-K, t^{*}\right) \\
c /\left(1+\alpha e^{-r\left(t^{*}-t\right)}\right) w \text { for } t \in\left(t^{*}-N-K, t^{*}-K\right) \\
c /(1-\theta) w \text { for } t>t^{*}
\end{array}\right.
$$

where the subsidy occurs in periods $t^{*}-N-K$ through $t^{*}-K$ and $0 \leq K \leq t^{*}-N$.

The individual's budget constraint may be written as

$$
\begin{aligned}
\int_{0}^{T} c e^{-r t} d t= & \int_{0}^{t^{*}-N-K} w H(t) e^{-r t} d t \\
& +\int_{t^{*}-N-K}^{t^{*} K}\left(1+\alpha e^{-r\left(t^{*}-t\right)}\right) w H(t) e^{-r t} d t \\
& \int_{t^{*}-K}^{r^{*}} w H(t) e^{-r t} d t+\int_{t^{*}}^{T}(1-\theta) w H(t) e^{-r t} d t .
\end{aligned}
$$

Using this budget constraint, along with the first order conditions,

$$
c^{*}(t)=1 / 2[1+\zeta \alpha-(1-\phi) \theta] w
$$

where $\zeta=\left(r N e^{-r *}\right) /\left(1-e^{-r T}\right)$.

Thus, $c^{*}(t)$ is independent of $K$ as was claimed in the next.

The years chosen for the subsidy must therefore be chosen on the basis of their utility of leisure. Since $L^{*}(t)$ is not affected by the choice of $K$ for $t \geq t^{*}$, it is sufficient to consider the alternative utilities of leisure through period $t^{*}$.

$$
\begin{aligned}
& \int_{0}^{t^{*}} U\left(L^{*}(t)\right) e^{-r} d t \equiv \int_{0}^{t^{*}}\left(\ln L^{*}(t)\right) e^{-r t} d t \\
& =\int_{0}^{*} c^{*} e^{-r t} d t-G(K)
\end{aligned}
$$


where

$$
\begin{aligned}
G(K) \equiv \int_{0}^{*-N-K}(\ln w) e^{-r t} d t & \left.+\int_{t^{*}-N-K}^{t^{*}-K} \ln \left[1+\alpha e^{-r\left(t^{*}-t\right)}\right) w\right] e^{-r t} d t \\
& +\int_{t^{*}-K}^{*}(\ln w) e^{-r t} d t .
\end{aligned}
$$

If $d G / d K>0$, then a lower $K$ (i.e., later subsidy) will increase utility. If $d G / d K<0$, then a higher $K$ (i.e., earlier subsidy) will increase utility. Differentiating above and simplifying,

$$
d G / d K=e^{-r\left(t^{\bullet}-K\right)}\left[e^{r N} \ln \left(1+\alpha e^{-r(N+K)}\right)-\ln \left(1+\alpha e^{-r K}\right)\right]
$$

which implies that $d G / d K>0$ if and only if

$$
\ln \left(1+\alpha e^{-r(N+K)}\right)>e^{-r N} \ln \left(1+\alpha e^{-r K}\right) .
$$

To prove that this inequality always holds, define $f(x)=\ln (1+x)$. Note that $f(x)$ is strictly increasing, strictly concave, and $f(0)=0$. Thus, is follows that $f(y x)>y f(x)$ for $0<y<1$. Setting $x=\alpha e^{-r K}$ and $y=e^{-r N}$, the conclusion follows. Consequently, $d G / d K>0$ and years $t^{*}-N$ through $t^{*}$ will exhibit the highest $N$ years of labor supply and effect the Social Security wage subsidy during these years.

\section{A More General Setting}

Consider a discrete model in which we wish to choose the $N$ years to be subsidized. For convenience, we will use continuous discounting factors as we did in the text, although discrete discounting works perfectly as well. Maximizing life-cycle utility subject to a life-cycle budget constraint, we set up the Lagrangean

$$
\mathcal{L}=\sum_{t=1}^{T} e^{-r t} U\left(c_{t}, L_{t}\right)+\lambda\left[\sum_{t=1}^{T}\left(e^{-r}+\alpha_{t} e^{-t^{*}}\right) w_{t} H_{t}-\sum_{t=1}^{T} e^{-t} c_{t}\right]
$$

where $w_{t}$ denotes the nominal wage rate at time $t$, exclusive of any wage subsidy, and $\alpha_{t}$ denotes the wage subsidy in year $t$. In our model, $\alpha_{t}=\alpha$ or 0 , depending on whether or not year $t$ is one of the $N$ years subsidized. Also in our model, $w_{t}=w$ or $(1-\theta) w$ depending on whether or not $t>t^{*}$.

Let $p_{t}=\left(e^{n t}+\alpha_{t} e^{r^{*}}\right) w_{t}$. Thus, $p_{t}$ denotes the present value at time $t=0$ of the total wage package, including the Social Security subsidy. Using the Envelope Theorem (or equivalently, using Roy's identity) and the chain rule, we can show that

$$
\frac{\partial \mathcal{L}^{*}}{\partial \alpha_{t}}=\lambda e^{-r^{*}} w_{t} H_{t},
$$

where $\mathcal{L}^{*}$ denotes the stationary value of the Lagrangean, i.e., $\mathcal{L} *$ is the indirect measure of utility. By construction of $\alpha_{t}$, if $\alpha$ is small, those years $t$ in which $\partial \mathcal{L}^{*} / \partial \alpha_{t}$ is greatest will be chosen to be subsidized.

In the text, $w_{t}$ is constant but $H_{t}$ is increasing for $t<t^{*}$. Consequently, the $N$ years immediately preceding $t^{*}$ will be chosen. If $w_{t}$ is also increasing, this would reinforce this conclusion, as stated in the concluding section of the text. 


\section{REFERENCES}

BECKER, G. [1965]: “A theory of the allocation of time”, Economic Journal, 75, 493-517.

BLINDER, A., GORDON, R. and WISE, D. [1980]: "Reconsidering the work disincentive effects of social security", National Tax Journal, 33 (December 1980), 431-443.

BLINDER, A. and WEISS, Y. [1976]: "Human capital and labor supply: A synthesis", Journal of Political Economy, 84 (June 1976), 449-473.

BURKHAUSER, R. and TURNER, J. [1978]: “A time-series analysis on social security and its effect on the market work of men at younger ages", Journal of Political Economy, 86, (August 1978), 701-715.

BURKHAUSER, R. and TURNER, J. [1981a]: “Is the social security payroll tax a tax?", Vanderbilt University, mimeo.

BURKHAUSER, R. and TURNER, J. [1981b]: "Can twenty-five million Americans be wrong? - A response to Blinder, Gordon and Wise", National Tax Journal, 34 (December 1981), 467-473.

CRAWFORD, V. and LILIEN, D. [1981]: "Social security and the retirement decision", Quarterly Journal of Economics, 96 (August 1981), 505-529.

DIAMOND, P. and MIRRLEES, J. [1978]: “A model of social insurance with variable retirement”, Journal of Public Economics, 10 (April 1978), 295-336.

HECKMAN, J. [1974]: "Life-cycle consumption and labor supply: An explanation of the relationship between income and consumption over the life-cycle", American Economic Review, 64 (March 1974), 188-194.

HECKMAN, J. [1986]: “A life-cycle model of earnings, learning and consumption”, Journal of Political Economy, 84 (August 1976), 911-945.

SHESHINSKI, E. [1978]: "A model of social security and retirement decisions", Journal of Public Economics, 10 (April 1978), 337-360. 